\title{
Recurrent Selection for Rubber Yield in Russian Dandelion
}

\author{
Katrina J.M. Hodgson-Kratky, Olivier M. Stoffyn, and David J. Wolyn ${ }^{1}$ \\ Department of Plant Agriculture, University of Guelph, 50 Stone Road East, Guelph, ON, Canada \\ $N 1 G 2 W 1$
}

\begin{abstract}
AdDITIONAL INDEX wORDs. natural rubber, half-sib family, Taraxacum kok-saghyz, rubber percentage, root dry weight
Abstract. Russian dandelion [Taraxacum kok-saghyz (TKS)] is a promising alternative to the Para rubber tree (Hevea brasiliensis) as a source of natural rubber; however, rubber yields must be improved for this undomesticated species to become a profitable new crop. Half-sib family recurrent selection was conducted for four cycles to increase rubber yield, estimated as the product of rubber percentage, and root dry weight per plant. Two distinct populations were developed for adaptation to sand and loam soil types. Rubber percentage increased from $4.17 \%$ for the cycle $0\left(C_{0}\right)$ population to $6.40 \%$ for the $\mathrm{C}_{4}$-loam population. Rubber yield also increased from 0.15 to $0.22 \mathrm{~g} / \mathrm{plant}$ after four selection cycles. Although phenotypic variation was observed, selection had no effect on root weight; all populations averaged $3.70 \mathrm{~g} /$ plant. Rubber yield and percentage and root dry weight were not increased after four selection cycles on sandy soils, likely because of poor adaptation and high environmental variation. Year and soil type affected rubber yields; however, rubber percentage was more stable than root dry weight. Overall, russian dandelion can be improved for rubber yield, and further studies with increased error control should be considered to enhance root dry weight.
\end{abstract}

Natural rubber is an essential material used in more than 50,000 products, including tires and medical equipment, because of its intrinsic properties such as impact resistance and high elasticity (Cornish, 2017). This strategic commodity is mainly produced by the Para rubber tree, which has specific climate requirements, limiting most cultivation to Southeast Asia (Fox, 2014). Production has been constrained over the past 30 years by conversion of land to palm oil plantations (Dallinger, 2011), and trees are vulnerable to environmental threats, such as disease and climate change, due to low genetic diversity (van Beilen and Poirier, 2007). Increased demand for natural rubber in the future may not be satisfied by rubber tree production alone (Cornish, 2017); therefore, alternative crops are being developed worldwide.

Russian dandelion (TKS) is a promising alternative to the rubber tree (Cornish, 2017). Specialized cells, laticifers, in fleshy tap roots produce milky latex in which rubber particles are suspended (Whalen et al., 2013). Coagulated latex produces solid rubber with properties similar to that derived from the rubber tree. The species is suited to a temperate climate and can be grown in parts of Europe and North America along latitudes similar to those of its native habitats in Kazakhstan, Uzbekistan, and northwestern China (Cornish, 2017). Unlike many dandelion species, TKS is diploid $(2 n=16)$ and sexually reproducing with enforced outcrossing through self-incompatibility (Warmke, 1943). Although a perennial, the plant can be easily incorporated into annual cropping systems.

Extensive TKS cultivation and research was conducted during World War II, during a natural rubber shortage (Whaley and Bowen, 1947). Rubber from this species accounted for $30 \%$ of that consumed in the USSR in 1941 (Ulmann, 1951, as cited in van Beilen and Poirier, 2007); however, the species proved difficult to grow and yields were low. Rubber percentage and rubber yield in wild accessions averaged $4.4 \%$ of dry weight

Received for publication 30 Aug. 2017. Accepted for publication 29 Sept. 2017. Funding was provided by Bridgestone Americas, Inc. and the Ontario Ministry of Agriculture, Food and Rural Affairs.

${ }^{1}$ Corresponding author. E-mail: dwolyn@uoguelph.ca. and $110 \mathrm{~kg} \cdot \mathrm{ha}^{-1}$, respectively, across trials conducted in Minnesota, Wisconsin, and Michigan (Whaley and Bowen, 1947). Breeding was initiated for development of high-yielding lines; however, research was suspended after World War II when rubber shortages ceased, and improved TKS germplasm was lost (Kirschner et al., 2013). Thus, initiation of breeding programs today requires access to wild germplasm.

Increasing both root weight and rubber percentage is important for improving rubber yield (Cornish et al., 2016). These traits were not correlated or correlated negatively in both TKS (Cornish et al., 2016; Filippov, 1941, as cited in Whaley and Bowen, 1947), and guayule (Parthenium argentatum), a rubber-producing desert plant (Dierig et al., 1989; Ray et al., 1993; Thompson et al., 1988); consequently, selection for only one parameter may not always improve rubber yield. In guayule, single-plant selection for both root weight and rubber percentage increased rubber yield 300\% (Ray et al., 2010). Four years of selection in Russia during World War II produced TKS germplasm with $24.5 \mathrm{~g} /$ plant root weight and $15 \%$ rubber (Koroleva, 1940, as cited in Whaley and Bowen, 1947).

Although TKS can be grown on sandy soils, those with loam to silty clay loam classifications are optimal for productivity (Whaley and Bowen, 1947). Development of germplasm adapted to different soils could expand acreages suitable for this crop and decrease demand on land used for food production. In areas such as the sandplains of Southern Ontario, where profitable replacement crops for tobacco (Nictotiana tabacum) can benefit growers, breeding TKS for adaptation to light-textured sandy soils could have positive impacts. The objective of this research was to assess the effectiveness of recurrent selection for increasing rubber yield in populations selected separately on sandy and loam soils.

\section{Materials and Methods}

\section{Breeding strategy}

Establishment of a $\mathbf{C}_{0}$ Population. One hundred individuals for each of 20 TKS PIs (Hodgson-Kratky et al., 2015) were 
grown and evaluated for rubber yield in 2011. The best 200 plants were selected, including at least five plants from each PI to maintain genetic diversity. Only half survived to flower and the plants were mated randomly. Seed was saved from individuals to generate 100 half-sib families which constituted the $\mathrm{C}_{0}$ population.

HALF-Sib FAMILY RECURRENT SELECTION. In 2012, the $100 \mathrm{C}_{0}$ half-sib families were planted on both sand and loam soils to develop separate, adapted populations. The best 10 families for rubber yield per plant on each soil type were selected, and 10 random plants within these families were chosen for pollination. The 100 plants from each soil type were mated randomly to generate 100 half-sib families constituting $\mathrm{C}_{1}$-sand and $\mathrm{C}_{1}$-loam populations which were grown on their respective soil types in 2013. The selection procedure was repeated for each population to produce $\mathrm{C}_{2}-\mathrm{C}_{4}$ sand and loam generations from 2014 to 2016, respectively. Genetic gain was evaluated by comparing control and improved populations at three locations in 2016.

\section{Field design}

SELECTION EXPERIMENTS. The 20 PIs were planted in a randomized complete block design (RCBD) with two replicates grown on Bookton sandy loam soil. For $\mathrm{C}_{0}-\mathrm{C}_{3}$ generations, families were planted in a RCBD with two blocks for the populations grown on each of the two soil types, sand and loam, from 2012 to 2015, respectively. In 2016, only the $\mathrm{C}_{4}$ families for the loam population were planted in four replications. For the $\mathrm{C}_{0}$ to $\mathrm{C}_{4}$ populations, 24 plants were planted per family for each block except for families with poor germination or limited seed number, which had as few as 10 plants per block. The $C_{0}$ population was grown as a control with each subsequent generation from 2013 to 2016, with two to six replications in each block. The sand and loam populations were grown on loamy very fine sand to loamy sand and sandy loam to loam soils, respectively, at the Simcoe Research Station (SRS), Simcoe, ON, Canada (lat. $42^{\circ} 51^{\prime} \mathrm{N}$, long. $80^{\circ} 16^{\prime} \mathrm{W}$, elevation $240.5 \mathrm{~m}$ ).

GENETIC GAIN EXPERIMENT. To estimate gain from selection, five populations $\left(\mathrm{C}_{0}, \mathrm{C}_{2}\right.$-sand, $\mathrm{C}_{4}$-sand, $\mathrm{C}_{2}$-loam, and $\mathrm{C}_{4}$-loam), were evaluated simultaneously in 2016. An equal amount of residual seed from each family was bulked for each population. The plants were planted at each of four locations, two with loam and two with sand soils, each with four replications in a RCBD with 100 plants for each population per replication. Soil classifications were Beverly-loamy phase loam (Loam site 1), Toledo-loamy phase loam (Loam site 2), Scotland sand (Sand site 1), and Tavistock sand (Sand site 2).

\section{Plant culture}

Selection experiment. Before planting the PIs and $\mathrm{C}_{0}-\mathrm{C}_{4}$ generations, the seed was stratified on moistened filter paper in petri dishes for $24 \mathrm{~h}$ at $4{ }^{\circ} \mathrm{C}$. The PIs were planted at the end of March, the $\mathrm{C}_{0}-\mathrm{C}_{3}$ generations were planted between the last week of April and first 2 weeks of May, and the $\mathrm{C}_{4}$-loam was planted during the first week of April. All seeds were planted in 200-cell trays filled with soilless medium (Sunshine Mix \#5; Sun Gro Horticulture, Vancouver, BC, Canada). The plants were grown in a greenhouse at $21 / 18^{\circ} \mathrm{C}$ (day/night), with a $16-\mathrm{h}$ photoperiod, provided by high-pressure sodium lamps (50-70 $\left.\mu \mathrm{mol} \cdot \mathrm{m}^{-2} \cdot \mathrm{s}^{-2}\right)$ and fertigated on alternate weeks with $20 \mathrm{~N}-$ $3.5 \mathrm{P}-16.6 \mathrm{~K}$ at a concentration of $1.5 \mathrm{~g} \cdot \mathrm{L}^{-1}$. The plants were transplanted into the field at the SRS in mid-May (PIs and $\mathrm{C}_{4}$-loam) and mid-June $\left(\mathrm{C}_{0}-\mathrm{C}_{3}\right)$. Before planting, field sites were sampled and fertilizer was applied according to the nutrient recommendations for carrot [Daucus carota ssp. sativus (Ontario Ministry of Agriculture, Food and Rural Affairs, 2014)]. The PIs were planted in rows consisting of $\approx 50$ plants spaced $10 \mathrm{~cm}$ apart and families of the $\mathrm{C}_{0}-\mathrm{C}_{4}$ populations were planted in rows consisting of 24 plants spaced $5 \mathrm{~cm}$ apart. For the PIs and $\mathrm{C}_{0}-\mathrm{C}_{3}$, rows were spaced $76 \mathrm{~cm}$ apart, and the plants were irrigated manually immediately after planting. $\mathrm{C}_{4}$ families were spaced $1 \mathrm{~m}$ between rows and watered for $7 \mathrm{~d}$ after planting and once in August because of drought. Guard rows were planted at the edges of all fields. Throughout the season, rows were weeded mechanically and manually as needed.

Genetic GAIN EXPERIMENT. The plants were grown as described above with the following modifications. Seeds were planted in the greenhouse between 6 and 8 Apr. 2016, and the trays were randomized weekly throughout the greenhouse to control for position effects. The transplants were planted in the field between 25 and 27 May 2016. Each row consisted of 100 plants spaced $5 \mathrm{~cm}$ apart with 1-m spacing between rows. Plants were irrigated manually with a water hose immediately after planting. Because of drought conditions, the plants were irrigated daily for $7 \mathrm{~d}$ after planting, then three times weekly in June and July, twice weekly in August, and once weekly until harvest unless $\geq 2.5 \mathrm{~cm}$ precipitation fell within 1 week.

\section{Harvesting and plant processing}

Selection EXPERIMENT. Whole plants were harvested manually (PIs, $\mathrm{C}_{0}-\mathrm{C}_{2}$ ) or mechanically with a potato digger (Niplo D-65A; Matsuyama Co., Ueda, Japan) $\left(\mathrm{C}_{3}\right.$ and $\left.\mathrm{C}_{4}\right)$ during the last week of October or first week of November. Plants were moistened and placed at $4{ }^{\circ} \mathrm{C}$ for up to $3 \mathrm{~d}$ before processing. For the PIs and $\mathrm{C}_{0}$, roots were severed $1-2 \mathrm{~cm}$ below the crown, dried at $45{ }^{\circ} \mathrm{C}$ for $3 \mathrm{~d}$, weighed, and analyzed for rubber percentage. Crowns were processed and stored for vernalization as described previously (Hodgson-Kratky et al., 2015). For the $\mathrm{C}_{1}-\mathrm{C}_{4}$ generations, 20 plants per family were stored for vernalization, with equal numbers from each replicate, and the remaining plants were dried for rubber quantification. Soil and leaves were removed from dried plants before analysis.

GenetiC GaIn EXPERIMENT. Plots were harvested mechanically on 28 Oct. 2016. Survival was determined by counting the number of plants per plot. The plants were dried at $45^{\circ} \mathrm{C}$ for $3 \mathrm{~d}$ and stored at room temperature until processing.

REPLANTING AND POLLINATION-SELECTION EXPERIMENT. After vernalization, plants of selected families were planted into 1-L pots filled with soilless medium (Sunshine Mix \#1, SunGro Horticulture) in late-December or early-January, placed in a greenhouse, and grown as described above, except plants were cultivated initially at $15 / 13{ }^{\circ} \mathrm{C}$ (day/night) for 4 weeks to synchronize flowering. Selected PIs were randomly mated daily using a feather. Ten plants from each selected family for populations grown on sand or loam were placed in separate isolation cages made of floating rowcover $\left(\mathrm{C}_{0}-\mathrm{C}_{2}\right)$ (GG-34; Gintec Shade Technologies, Vanessa, ON, Canada) or polyethylene fabric with improved light transmission $\left(\mathrm{C}_{3}-\mathrm{C}_{4}\right)$ (Econet T, Gintec Shade Technologies) and intercrossed randomly with house flies (Musca domestica) $\left(\mathrm{C}_{0},\right)$ or bumblebees [Bombus impatiens (Biobest Canada, Leamington, ON, Canada)] $\left(\mathrm{C}_{1}-\mathrm{C}_{4}\right)$.

Rubber ANALysis. For the PIs, the largest dried root from each plant was broken, and the rubber strands extending between the two halves was visually rated on a scale of 1 to 5 
$(1=$ small amount of rubber; $5=$ large amount of rubber). Rubber yield per plant was estimated as root dry weight $X$ rubber rating. For $\mathrm{C}_{0}-\mathrm{C}_{4}$ breeding generations and the genetic gain experiment, dried roots for each plot were bulked, weighed, and ground to a fine powder using a blender (Waring 7010S; Conair Corp., East Windsor, NJ). From each sample, $250 \pm 0.5 \mathrm{mg}$ was aliquoted into $30-\mathrm{mL}$ high-strength glass tubes with screw-on caps (Kimax HS 45500-30; Kimble Chase Life Science and Research Products, Vineland, NJ). Ten milliliters of acetone was added to each tube, which was shaken on an orbital shaker at $100 \mathrm{rpm}$ for $48 \mathrm{~h}$. The tubes were centrifuged at 2,118 $g_{\mathrm{n}}$ for $10 \mathrm{~min}$ and the acetone with dissolved resin discarded. For each tube, $10 \mathrm{~mL}$ of hexane was added, shaken at $100 \mathrm{rpm}$ for $24 \mathrm{~h}$, and then centrifuged at $2118 g_{\mathrm{n}}$ for $5 \mathrm{~min}$. After evaporating the hexane, the remaining rubber was weighed and rubber percentage was estimated. For each plot, rubber yield per plant was calculated as [average root dry weight per plant $\times$ (percent rubber/100)].

\section{Statistical analyses}

Genetic Gain EXPERIMent. An analysis of variance (ANOVA) was used to compare population means for rubber percentage, rubber yield per plant, root dry weight per plant, and percent survival. Data were fit to a generalized linear mixed model using PROC GLIMMIX in SAS (version 9.4; SAS Institute, Cary, NC). Population was considered a fixed effect and site and block nested within site were random effects. Sand site 2 was excluded from the analysis because most of the plants died shortly after planting. The assumptions of normality, homogeneity, and random distribution of error were tested using the Shapiro-Wilk statistic, Levene's test, and by visual analysis of residual plots, respectively. For rubber yield and root dry weight per plant, a covariance structure which had heterogeneous error over site was specified based on results from the assumption tests. For percent survival, a covariance structure with heterogeneous error for population was specified. Bias was corrected using the Kenward-Roger adjustment (Bowley, 2015). A likelihood ratio test was used to determine if the random interaction between site and population differed from zero. Least square means were separated using Tukey's honestly significant difference and significance was determined at $P \leq 0.05$.

COEFFICIENT OF VARIATION AND CORRELATION. ANOVAs were used to generate mean square error (MSE) values for rubber percentage, rubber yield, and root dry weight for $\mathrm{C}_{0}-\mathrm{C}_{4}$ populations grown on each soil type from 2012 to 2016, respectively, using PROC GLM in SAS (version 9.4). Fixed effects were half-sib family and block. Coefficients of variation were calculated using the following formula: $100 \sqrt{ } \mathrm{MSE} /$ mean of half-sib families. Correlation coefficients among rubber percentage, rubber yield, and root dry weight were estimated using PROC CORR in SAS (version 9.4) for family means of all generations $\left(\mathrm{C}_{0}-\mathrm{C}_{4}\right)$.

REALIZED heritability. Realized heritability was estimated as the regression coefficient $(b)$ of the cumulative response plotted against the cumulative selection differential (Falconer, 1981) for all generations of each of the sand and loam populations using PROC REG in SAS.

\section{Results}

The ANOVA for $\mathrm{C}_{0}, \mathrm{C}_{2}$, and $\mathrm{C}_{4}$ breeding populations planted at three sites indicated that the effect of population was significant for rubber percentage, rubber yield per plant, and percent survival but not for root dry weight per plant. The interaction effect between replicate site and population was not significant for all variables; therefore, data were pooled over the three replicate sites.

Half-sib family recurrent selection increased rubber percentage and rubber yield over four cycles (Fig. 1A and B). Values in the $\mathrm{C}_{4}$-loam population were $54 \%$ and $45 \%$ greater than that of the $\mathrm{C}_{0}$ control, representing selection gains of

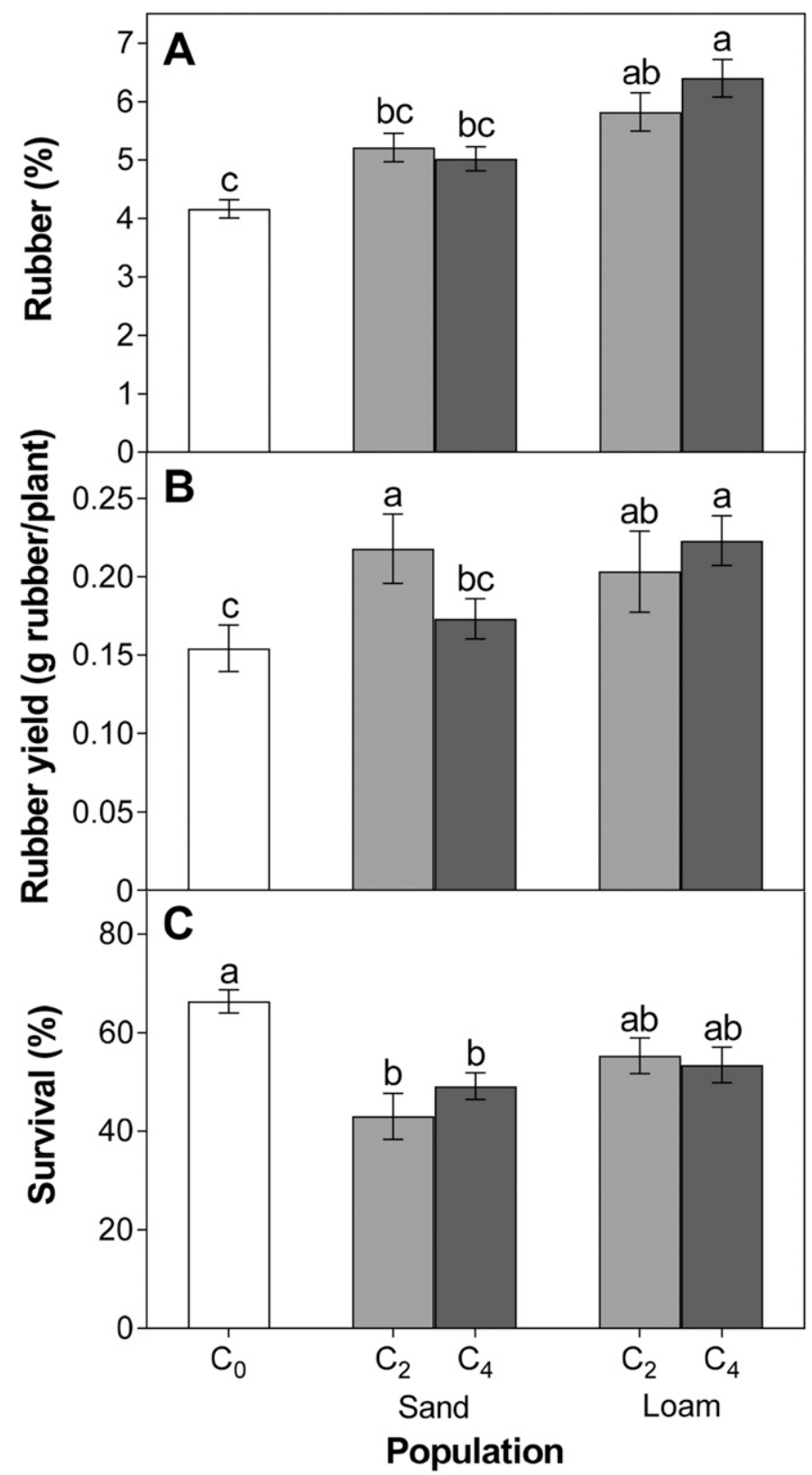

Fig. 1. Genetic gain evaluation of russian dandelion populations developed for high rubber yield on sand or loam soil types using half-sib family recurrent selection. Cycle $0\left(\mathrm{C}_{0}\right), \mathrm{C}_{2}$, and $\mathrm{C}_{4}$ populations were assessed for $(\mathbf{A})$ rubber percentage, (B) rubber yield, and (C) percent survival at one location with sandy soil and two locations with loam soil at the Simcoe Research Station, Simcoe, ON, Canada in 2016. Means $\left(n=12, \mathrm{C}_{0}\right.$ and $\mathrm{C}_{4}$-loam; $n=11, \mathrm{C}_{4}$-sand; $n=10, \mathrm{C}_{2}$-sand and $\mathrm{C}_{2}$-loam), pooled over locations, are presented \pm standard error. Letters indicate significance according to Tukey's honestly significant difference $(P \leq 0.05)$. 
$13.5 \%$ and $11.3 \%$ per cycle for rubber percentage and rubber yield, respectively. $\mathrm{C}_{2}$ - and $\mathrm{C}_{4}$-loam populations did not differ, although both were greater than the $\mathrm{C}_{0}$. Rubber percentage did not differ among the $\mathrm{C}_{0}, \mathrm{C}_{2}$-sand, and $\mathrm{C}_{4}$-sand populations. Rubber yield of $\mathrm{C}_{2}$-sand was greater than that for the other two populations, which did not differ. Root dry weight ranged from 3.39 to $4.00 \mathrm{~g} /$ plant for the five populations (data not shown). The greatest dry weight was observed in the $\mathrm{C}_{2}$-sand population which could explain why rubber yield was high in this population. Percent survival in the $\mathrm{C}_{0}$ was greater than that of the advanced sand populations (Fig. 1C), whereas the $\mathrm{C}_{2}$ and $\mathrm{C}_{4}$ loam populations did not differ from the $\mathrm{C}_{0}$ or the sand populations. Among half-sib families over generations, rubber percentage and root dry weight per plant were correlated moderately $(r=0.50, P<0.0001)$.

Phenotypic variation within populations was greatest for rubber yield and least for dry weight when considering selection differentials expressed as SDs (Table 1). These values also appeared to decrease with advancing selection cycles, suggesting loss of genetic variability. Coefficients of variation averaged over cycles were $27 \%, 44 \%$, and $31 \%$ for rubber percentage, rubber yield, and root dry weight, respectively, and
$30 \%$ and $39 \%$ for loam and sand, averaged over populations, respectively. Realized heritabilities were greatest for rubber percentage and most traits in the loam population (rubber percentage: loam $=0.40$, sand $=0.25$; rubber yield: loam $=0.23$, sand $=0.15$; dry weight: loam $=0.00$, sand $=0.00$ ).

In a comparison of one population $\left(\mathrm{C}_{0}\right)$ grown over 4 years on two soil types, rubber percentage was more stable compared with other traits, varying 1.54-fold (Fig. 2A). Rubber yield and root dry weight per plant were highly variable, $\approx 4$-fold, over the years and soil types of the experiment (Fig. 2B and C). Loam soils appear best for russian dandelion; mean rubber percentage, rubber yield, and root dry weight were 1.16-, 1.80-, and 1.62-fold higher, respectively, on loam than sandy soil from 2012 to 2015.

\section{Discussion}

Four cycles of recurrent selection increased rubber yield nearly $50 \%$ in a population grown on loam soils, whereas no response was observed when selecting and testing on sandy soils. Only the rubber percentage component of rubber yield increased; root dry weight did not change. Analysis of one population, $\mathrm{C}_{0}$, over years and soil types indicated that rubber

Table 1. Rubber percentage, rubber yield, root dry weight, selection differentials, and coefficients of variation (cv) of russian dandelion, cycle $0\left(\mathrm{C}_{0}\right)$ to $\mathrm{C}_{4}$, populations grown at the Simcoe Research Station, Simcoe, ON, Canada, from 2012 to 2016. Separate populations were subjected to half-sib family recurrent selection on sand or loam soil types.

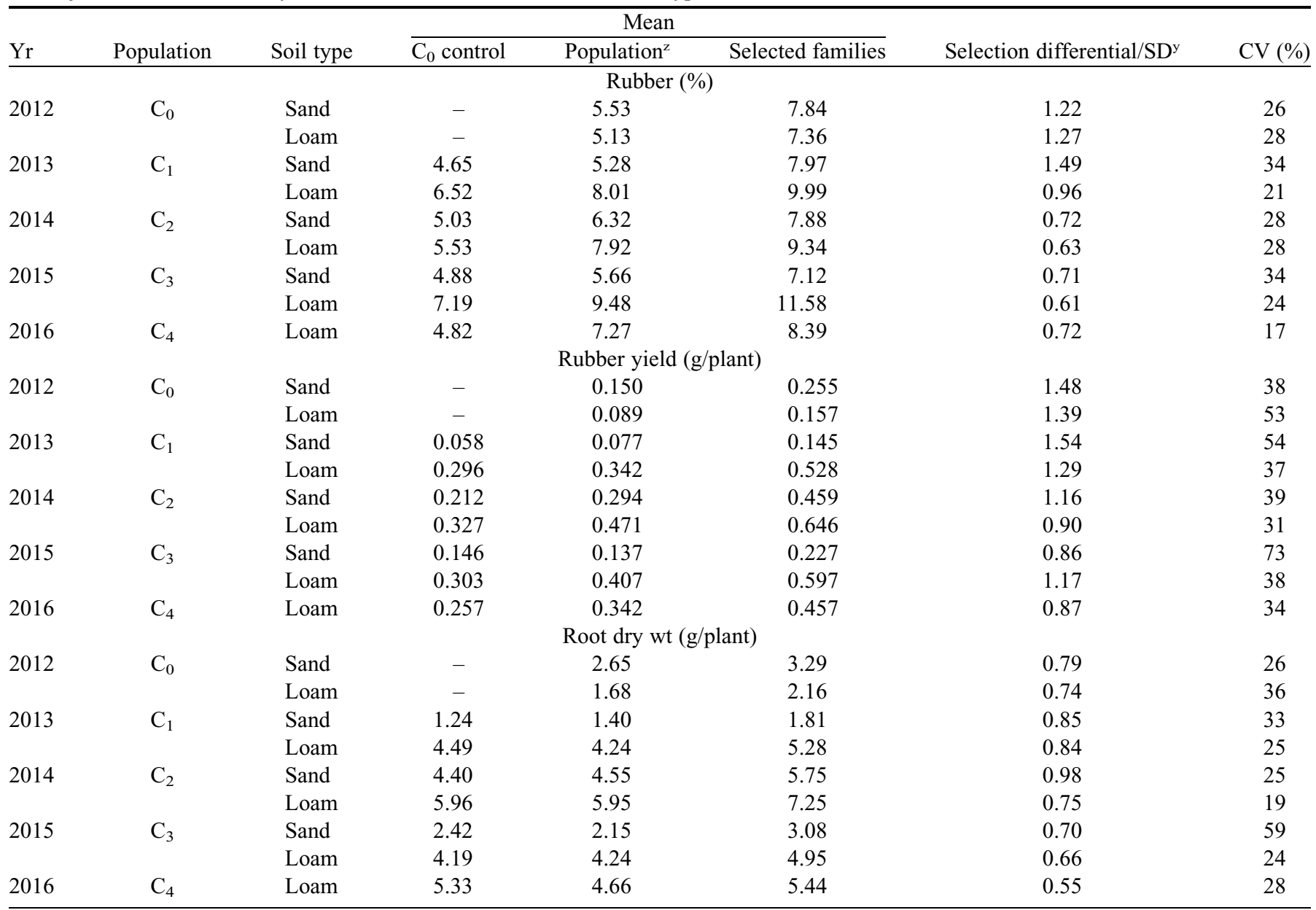

${ }^{\mathrm{z}}$ Population means were calculated based on values generated during the selection experiment in the respective year for each population. Means do not include data generated from the genetic gain experiment where $\mathrm{C}_{0}, \mathrm{C}_{2}$, and $\mathrm{C}_{4}$ populations were compared together at three sites in 2016 .

${ }^{\mathrm{y}}$ Selection differential $=$ selected families mean - population mean. 


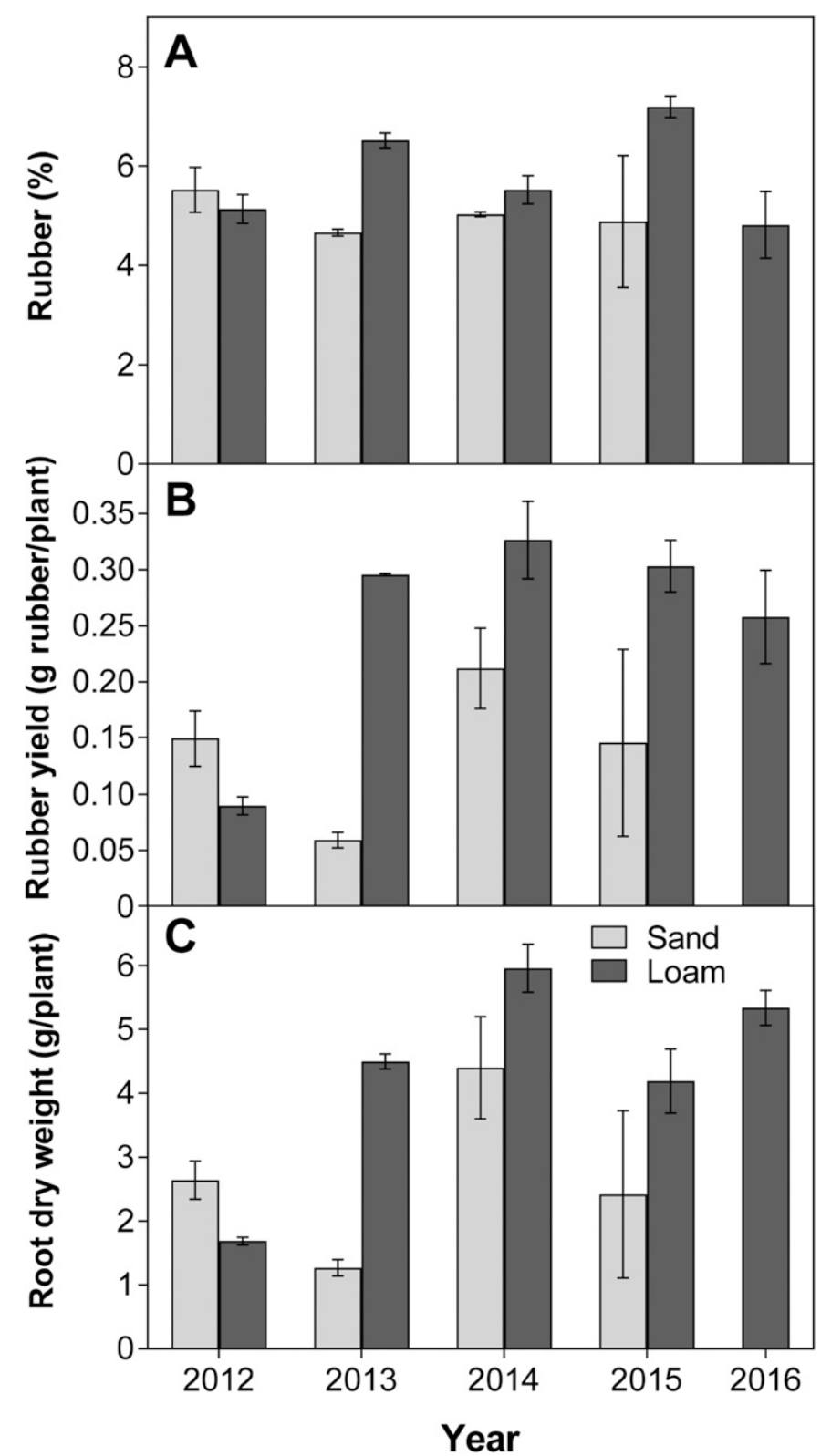

Fig. 2. (A) Rubber percentage, (B) rubber yield, (C) and root dry weight in the russian dandelion cycle $0\left(\mathrm{C}_{0}\right)$ control population grown in sand and loam soils at the Simcoe Research Station, Simcoe, ON, Canada, from 2012 to 2016. Means ( $n=2,2012$ to $2015 ; n=4,2016)$, are presented \pm standard error between blocks. Individual $\mathrm{C}_{0}$ families were grown in two replicate blocks in 2012 and block means were estimated; bulked seed among $C_{0}$ families was evaluated in replicate blocks from 2013 to 2016.

percentage is more stable over environments than root dry weight, which is more variable on sandy than loam soils.

Previous breeding efforts to improve russian dandelion reported 15\% rubber after four selection cycles (Koroleva, 1940, as cited in Whaley and Bowen, 1947). The discrepancy with the results described here is likely explained by the reporting of performance for the best lines within a breeding population, rather than the population average. The highest value observed for an individual half-sib family in the present study was $14.6 \%$ rubber.

The lack of response observed for root dry weight after four selection cycles, for the populations bred on sand or loam soils, occurred even though there was phenotypic variation for the trait and selection differentials were nearly the same as those for rubber percentage. The lack of genetic gain and resulting realized heritability of zero can be caused by high environmental error, low genetic variance, or both. Coefficients of variation were similar for rubber percentage and root weight, suggesting that genetic variance may have been low for the latter. Alternatively, potential gains for root weight could be negated by mild inbreeding depression resulting from restricted population sizes. Decreasing selection intensity or increasing the number of families in the breeding population may be warranted with this undomesticated species. Selfing TKS plants was shown to not only decrease vigor but also germination such that plants could not be recovered after three generations (T. Di and D.J. Wolyn, unpublished data). Many other naturally crosspollinated species including maize [Zea mays (Good and Hallauer, 1977)], carrot (Simon, 2000), and alfalfa [Medicago sativa (Tysdal et al., 1942)] have also exhibited severe inbreeding depression from sib-mating or selfing.

Poor genetic gain for rubber yield and percentage in the populations bred on sandy soil was likely the result of low heritability from high environmental error. The coefficient of variation, averaged over the three parameters and the populations bred on sand, was $10 \%$ higher than that for loam. In addition, heterogeneity was often visible in plots on sandy soils as patches of healthy, vigorous plants where water pooled, and plants of low vigor in dry areas during drought, in patterns that could not be accommodated by blocking. The high variability of the $\mathrm{C}_{0}$ population on sandy soils over years and low yields compared with the population on loam soils further indicates the challenges to breed for broad adaptation and develop an economically viable crop for diverse soil types. TKS generally prefers soils with organic matter (OM) content greater than $2 \%$ that have adequate moisture retention (Whaley and Bowen, 1947). The sand locations at the SRS, used for the duration of this experiment (2011-16), averaged 1.5\% OM, whereas the loam locations had 2.5\% OM. Development of TKS germplasm with broad adaptation, including that for sandy soils, would have been useful for expanding the range of cultivation and especially provide a replacement crop for tobacco in the sandplains of Southern Ontario, Canada.

Increasing replications would be an effective solution for reducing environmental variance that decreases heritability and prevents efficient genetic gains; however, several factors constrain the progress. Seed quantity obtained from individual plants in a half-sib family recurrent selection program can restrict the number of replications and individuals per plot. Although several hundred seeds may be obtainable from one plant to produce a half-sib family, poor germination and establishment (Hodgson-Kratky et al., 2017; Moussavi et al., 2016) limits direct seeding of TKS because over-seeding requirements constricts the number of replicate plots. Seeding in the greenhouse can result in high germination; however, transplanting is time consuming and labor intensive and limits the number of plants and replicates when budgetary constraints are a factor.

Percentage survival of advanced populations bred on sand decreased compared with the $\mathrm{C}_{0}$ when they were grown with adequate irrigation on sand or loam soils. Inbreeding depression is a common cause of reduced survival in plants (Charlesworth and Willis, 2009) and could contribute to these results, whereby a narrow genetic base was selected under the stressful conditions 
of sand which was manifested as decreased seedling survival. Stressful environments often exaggerate the effects of inbreeding depression (Hoffman and Parsons, 1991) and may also explain why survival was lowered for sand whereas that for populations bred on loam appeared to decrease but differences were not significant. Modifications to the breeding strategy to minimize inbreeding, such as increasing the number of families or decreasing selection intensity, should be considered.

A moderate positive correlation $(r=0.5)$ was observed between rubber percentage and root dry weight per plant; previous reports suggested no (Cornish et al., 2016) or negative associations in TKS (Filippov, 1941, as cited in Whaley and Bowen, 1947). The discrepancy could be related to the germplasm used here or environmental effects. If the positive correlation is not spurious and the heritability of root dry weight can be increased through improved replication, advancements for rubber yield could be accelerated.

Overall, half-sib family recurrent selection improved rubber yield in TKS; however, rubber percentage increased and root dry weight per plant did not change. The observed $11.3 \%$ gain per cycle for rubber yield is significant and indicates potential to substantially alter this trait over several years. Breeding to broaden the adaptation of TKS to sandy soils was not successful with the selection parameters used in this experiment, and inbreeding depression may be a factor when selecting from undomesticated germplasm. Thus, both population size and selection intensity should be considered carefully. Development of a rapid phenotyping methodology using near-infrared spectroscopy can be beneficial for selection by facilitating increased replication, precision, and ultimately gain from selection.

\section{Literature Cited}

Bowley, S. 2015. A hitchhiker's guide to statistics in biology: Generalized linear mixed model edition. Plants et al., Guelph, ON, Canada.

Charlesworth, D. and J.H. Willis. 2009. The genetics of inbreeding depression. Natl. Rev. Genet. 10:783-796.

Cornish, K. 2017. Alternative rubber crops: Why should we care? Technol. Innov. 18:245-256.

Cornish, K., S.L. Kopicky, S.K. McNulty, N. Amstutz, A.M. Chanon, S. Walker, M.D. Kleinhenz, A.R. Miller, and J.G. Streeter. 2016. Temporal diversity of Taraxacum kok-saghyz plants reveals high rubber yield phenotypes. Biodiversitas (Surak.) 17:847-856.

Dallinger, J. 2011. Oil palm development in Thailand: Economic, social, and environmental considerations, p. 24-51. In: M. Colchester and S. Chao (eds.). Oil palm expansion in south east Asia: Trends and implications for local communities and indigenous peoples. FPP and SW, Moreton-in-Marsh, England.

Dierig, D.A., A.E. Thompson, and D.T. Ray. 1989. Relationship of morphological variables to rubber production in guayule. Euphytica 44:259-264.
Falconer, D.S. 1981. Introduction to quantitative genetics. Longman, London, England.

Fox, J. 2014. Through the technology lens: The expansion of rubber and its implications in Montane Mainland southeast Asia. Conserv. Soc. 12:418-424.

Good, R.L. and A.R. Hallauer. 1977. Inbreeding depression in maize by selfing and full-sibbing. Crop Sci. 17:935-940.

Hodgson-Kratky, K.J.M., O.M. Stoffyn, and D.J. Wolyn. 2015. Harvest date, post-harvest vernalization and regrowth temperature affect flower bud induction in russian dandelion (Taraxacum koksaghyz). Can. J. Plant Sci. 95:1221-1228.

Hodgson-Kratky, K.J.M., O.M. Stoffyn, and D.J. Wolyn. 2017. Recurrent selection for improved germination under water stress in russian dandelion. J. Amer. Soc. Hort. Sci. 142:85-91.

Hoffman, A.A. and P.A. Parsons. 1991. Evolutionary genetics and environmental stress. Oxford University Press, Oxford, United Kingdom. Kirschner, J., J. Stepanek, T. Cerny, P. De Heer, and P.J. van Dijk. 2013. Available ex situ germplasm of the potential rubber crop Taraxacum koksaghyz belongs to a poor rubber producer, $T$. brevicorniculatum (Compositae-Crepidinae). Genet. Resources Crop Evol. 60:455-471.

Moussavi, A., S.Z.H. Cici, C. Luocks, and R.C. van Acker. 2016. Establishing field stands of Russian dandelion (Taraxacum koksaghyz) from seed in southern Ontario, Canada. Can. J. Plant Sci. 96:887-894.

Ontario Ministry of Agriculture, Food and Rural Affairs. 2014. Vegetable production guide 2014-2015. OMAFRA Publ. 838.

Ray, D.T., D.A. Dierig, A.E. Thompson, and M.M. Diallo. 1993. Parent-offspring relationships in apomictic guayule. J. Amer. Oil Chem. Soc. 12:1235-1237.

Ray, D.T., M.A. Foster, T.A. Coffelt, and C. McMahan. 2010. Guayule: Culture, breeding and rubber production, p. 384-410. In: B.P. Singh (ed.). Industrials crops and uses. CABI, Cambridge, MA. Simon, P.W. 2000. Domestication, historical development, and modern breeding of carrot. Plant Breeding Rev. 19:157-190.

Thompson, A.E., D.T. Ray, M. Livingston, and D.A. Dierig. 1988. Variability of rubber and plant growth characteristics among singleplant selections from a diverse guayule breeding population. J. Amer. Soc. Hort. Sci. 113:608-611.

Tysdal, H.M., T.A. Kiesselbach, and H.L. Westover. 1942. Alfalfa breeding. Univ. Nebraska, Agr. Expt. Sta. Bul. 124.

van Beilen, J.B. and Y. Poirier. 2007. Guayale and russian dandelion as alternative sources of natural rubber. Crit. Rev. Biotechnol. 27:217-231.

Warmke, H.E. 1943. Macrosporogenesis, fertilization, and early embryology of Taraxacum kok- saghyz. Bul. Torrey Bot. Club 70:164 173.

Whalen, M., C. McMahan, and D. Shintani. 2013. Development of crops to produce industrially useful natural rubber, p. 329-345. In: T.J. Bach and M. Rohner (eds.). Isoprenoid synthesis in plants and microorganisms: New concepts and experimental approaches. Springer-Verlag, New York, NY.

Whaley, W.G. and J.S. Bowen. 1947. Russian dandelion (kok-saghyz) an emergency source of natural rubber. Misc. Publ. No. 618. U.S. Govt. Printing Office, Washington, DC. 